\title{
Intra-myocardial Bullet causing heart block in a patient with multiple gunshot wounds: Case Report
}

Authors: Odhiambo W.A. ${ }^{1}$ BDS, MDS (OMFS), Guthua S.W. ${ }^{1}$ BDS, MMED SC, DOMS, FIAOMS, FCS, Munene J. ${ }^{2}$, MBChB, MMed, Kariuki C. ${ }^{3}$, MBChB, Mmed, FRCP Thanga P.W. ${ }^{3}$ MBChB. Affiliations: 1 Department of Oral and Maxillofacial Surgery, University of Nairobi, 2 Kenyatta National Hospital, Nairobi, 3 The Nairobi Hospital. Corresponding Author; Dr. Walter Odhiambo, Department of Oral and Maxillofacial surgery, School of Dental Sciences, College of Health Sciences. P.O. BOX 19676, KNH, NAIROBI Tel 254-20-3873398 Cell 254-722-518616.E-mail: walter.odhiambo@uonbi.ac.ke

\section{Summary}

Elective removal of intra-myocardial bullet remains a controversial subject. A non-operative approach has been recommended as appropriate for a stable asymptomatic patient. In the presence of complications such as bleeding, perforation leading to cardiac tamponade, thrombus formation, embolization, rhythm disturbances and infections, surgical removal may be advised. We present a patient who survived multiple gunshot wounds with a bullet lodged in the wall of the left ventricle of the heart. Details of the injuries sustained, operative removal of the bullet and the challenges that ensued are illustrated.

\section{Introduction}

Firearm injury is increasingly becoming a major public health problem in both developed and developing countries. The wounds caused by firearms, whether in assault, robbery, suicide or mass shootings, tend to be more lethal causing higher mortality and severer morbidity rates than other conventional weapons commonly used in assault $(1,2,3,4)$.

The injuries caused by firearms tend to be multiple even if arising from a single bullet and thus may involve multiple organs and affect diverse systems. Highly skilled specialists from different surgical and clinical discipline may be required to save life and to rehabilitate these patients. Penetrating cardiac injuries can be particularly devastating.

Elective removal of intra-myocardial bullet remains a controversial subject among cardiothoracic surgeons. A non-operative approach has been recommended as appropriate for stable, asymptomatic patient. Bullets retained in the myocardium may embolize, act as a nidus for infections or cause cardiac tissue necrosis. Other complications of retained intracardiac missiles include bleeding, perforation leading to cardiac tamponade, thrombus formation and rhythm disturbances. These complications are usually related to size and location of the missile. Although the natural course, long term complications and migratory potential are unpredictable and not well documented in the literature, many right and left ventricular injuries have been treated nonoperatively $(5,6,7,8)$.

We present a case of a multiply injured patient found to have a bullet lodged in his heart. Thoracotomy was necessary in this case as cardiac function was deteriorating.

\section{Case Summary}

We report the case of a 31-year old male who suffered multiple gunshot injuries from an attack by armed criminals. He was rushed to the hospital by his wife and neighbours. Arriving at the accident and emergency department of Nairobi Hospital within 20 minutes of the injury time he was managed following the Advanced Trauma Life Support (ATLS) protocol.

The patient arrived in the A\&E room talking, breathing spontaneously and with pulse present (blood pressure $115 / 70 \mathrm{mmHg}$ ). He was well oriented in time, place and person with a Glasgow Coma Score (GCS) of 15/15.

Further evaluation revealed injuries to the face, wounds on the right cheek and floor of the mouth with bullet entry wound noted in the left maxillary region and exit in the right submandibular region. Another entry was noted on the chest wall, mid-axillary line but no exit wound observed. The breath sounds were reduced on 
the right middle and lower third of the chest. A chest tube with under water seal drain (UWSD) was inserted and 500mls of blood drained.

The third injury site involved the right upper arm which had bullet entry and exit wounds. Wooden splint was applied to support the arm during the secondary survey. Radiographs taken during the orthopaedic review revealed comminuted compound fracture of the distal third of right humerus (Figure 1a.) Radiographs of the facial skeleton revealed compound maxillary dento-alveolar fracture with loss of some teeth and comminuted compound right mandibular angle fracture. (Figure 2a)

The patient's initial haemoglobin level was $13.5 \mathrm{~g} / \mathrm{dl}$. This dropped to $8.6 \mathrm{~g} / \mathrm{dl}$ within five hours. Two units of whole blood were transfused at this point. White blood cell count was $7500 / \mathrm{mm}^{3}$ at admission but rose to $12100 / \mathrm{mm}^{3}$ within five hours.

He was taken to the OR 2 hours post- in-

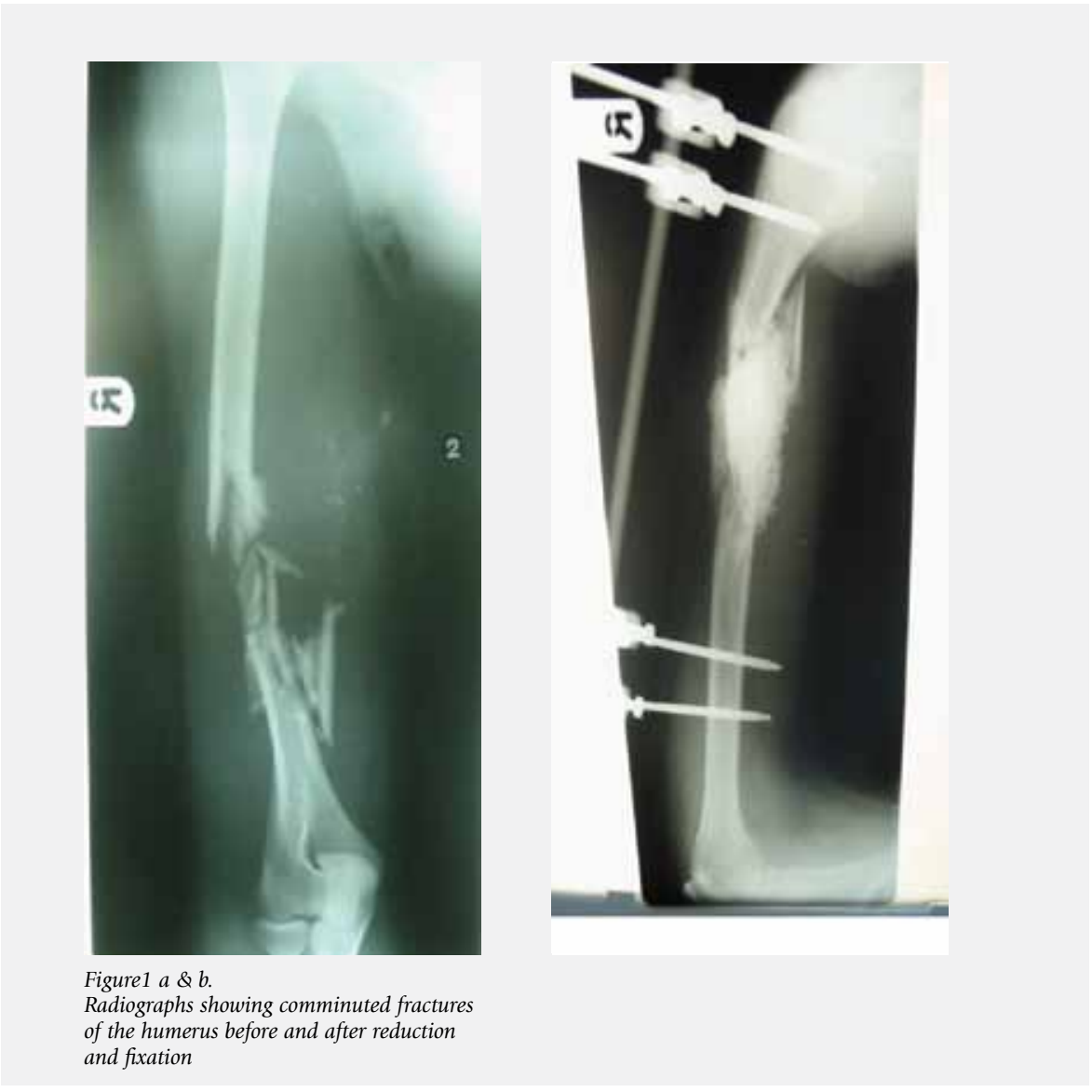
jury for surgical toileting of compound fractures and external stabilization of the extremity fracture. He was then admitted to the Intensive care unit for observation.

Twelve hours post-extubation, he developed acute respiratory distress syndrome (ARDS) and had to be re-intubated. Review of the initial chest radiographs showed right pulmonary contusion, haemothorax, left basal consolidation and bullet lodged above the diaphragm. The chest radiograph showed bullet lodged above the diaphragm. ARDS resolved markedly over the following 7 days. However, there were persistent bronchial breath sounds in the left lower lung with purulent secretions and collapse with consolidation. CT scan of the chest revealed left atelectasis with small pleural effusion.

Bronchoscopy ordered at this point showed scanty brownish secretions with no mucous plugs.

On the third day post-admission, a pansystolic murmur was detected on auscultation and traumatic ventricular septal defect (VSD) or mitral valve regurgitation (MR) suspected. He later developed first degree heart block, which evolved into complete heart block. An ECG showed a complete heart block with Left Bundle Branch

Block. In view of these signs the chest CT was reviewed by the radiologist and bullet seen and suspected to be lodged in the wall of the left ventricle (Fig.3).

Echocardiogram showed a hyperechoic shadow in the posterior wall near the posterior mitral valve leaflet and possibly protruding into the LV lumen. Removal of the bullet with cardiopulmonary bypass on stand by was therefore recommended. Repeat echo confirmed perimembranous VSD and eleven days from the day of injury; thoracotomy and open heart surgery for retrieval of bullet with VSD and right atrium repair was done. The bullet was found lodged behind the posterior mitral leaflet in the LV (Fig. 4). After the repairs pacing wires were placed in the right ventricle.

Pulmonary edema developed after open-heart surgery and resolved after 3 days of diuresis with lasix and vigorous chest physiotherapy. Patient was extubated on 2nd post-op day. Permanent pacemaker was inserted 2 weeks post operative and the patient did well post insertion.

The renal function was normal through out the admission period even though, an occasional potassium supplement was given. During this time, his humeral frac- 


\section{Intra-myocardial Bullet in a Multiple Firearm Injury Patient: Case Report}

Odhiambo W.A., Guthua S.W., Munene J., Kariuki C., Thanga P.W.
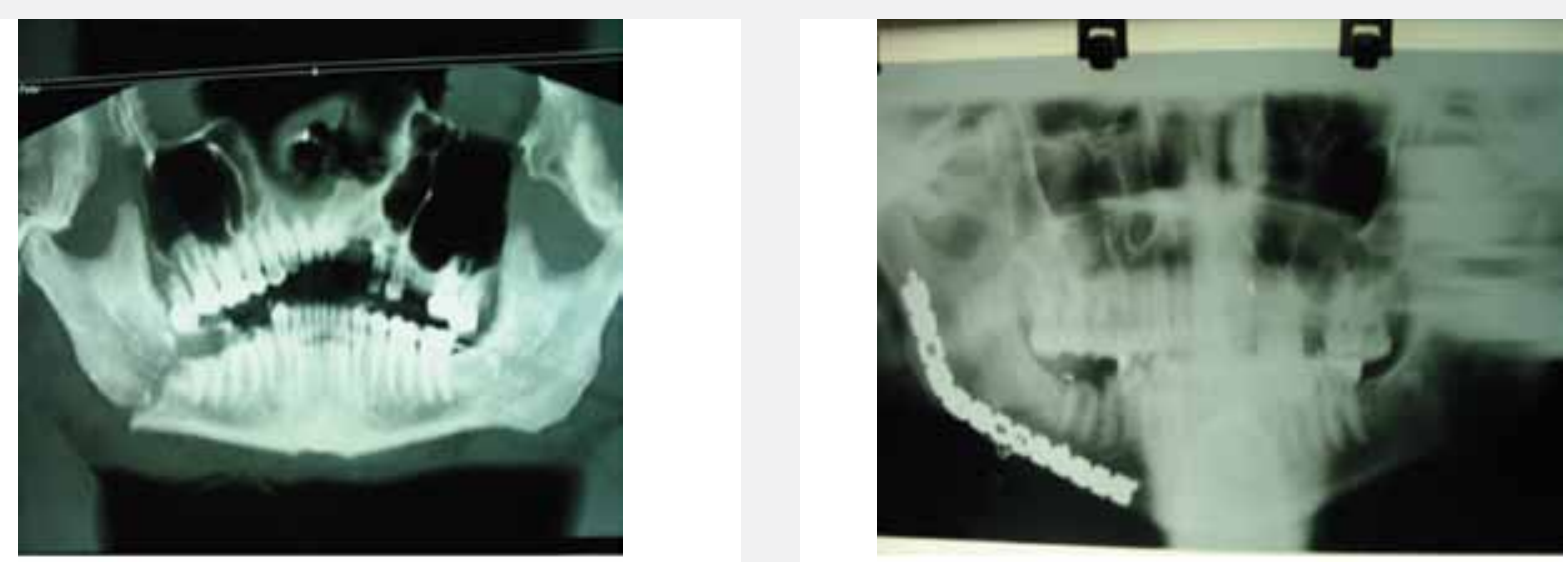

Figure $2 a \& b$.

Orthopantomogram scan showing comminuted mandibular

fracture before and after reduction and fixation with a

reconstruction plate.
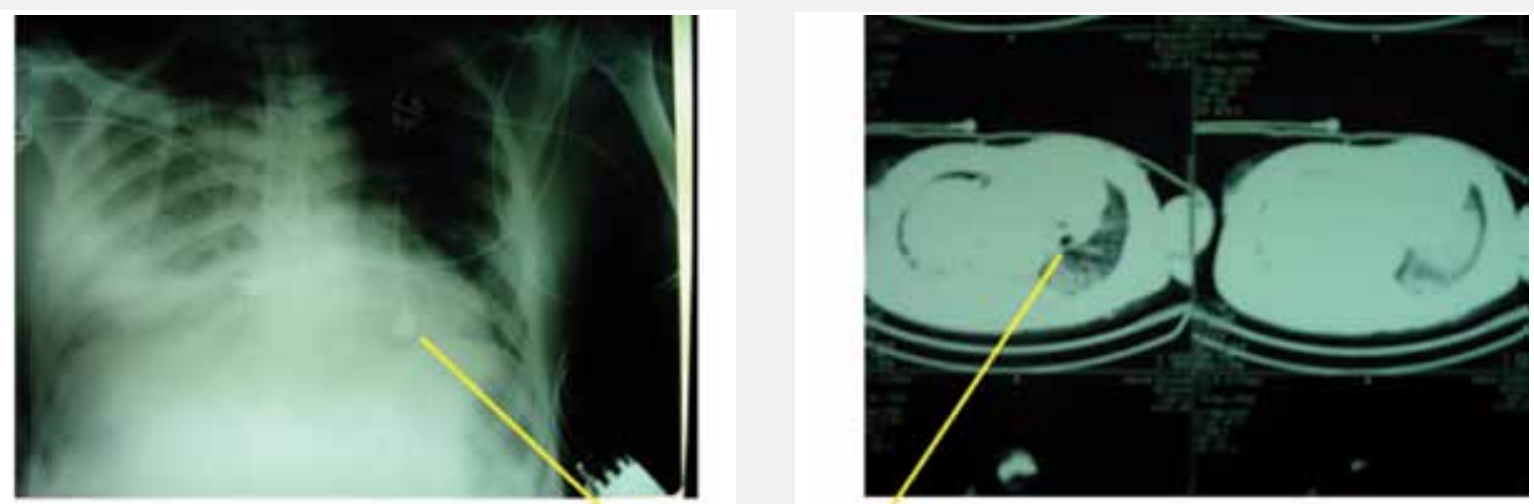

Figure 3.

CT scans of the chest showing the location of the

Bullet in the chest

bullet above the diaphragm.
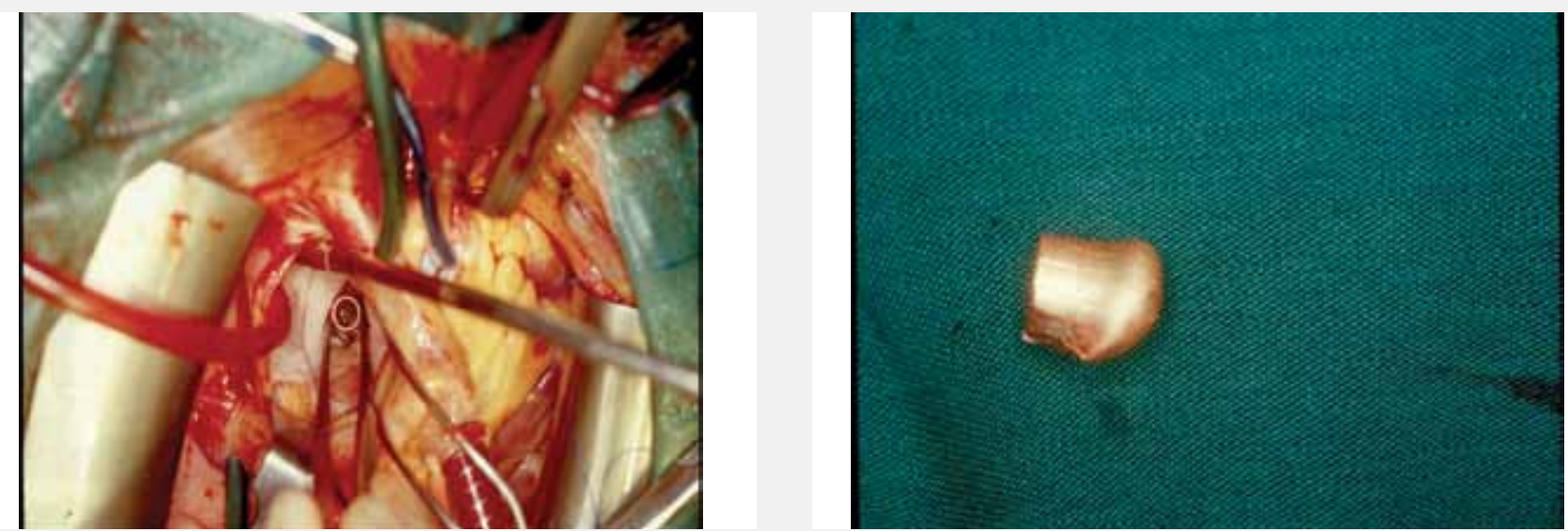

Figure 4

Photograph showing bullet in the heart and bullet fragment post- surgical recovery. 
ture was grafted with Tricalcium phosphate (Chron Os) (Figure 1b) and maxillofacial/ mandibular fractures reduced and rigidly fixed with a stainless steel reconstruction plate (Figure 2b). A total of 6 units whole blood and 4 units fresh frozen plasma (FFP) was transfused. He spent a total of 41 days in hospital; 20 days in ICU, 4 days in high dependency unit and another 17 days in the surgical ward before being discharged in a stable condition. Two years since the operation was carried out, the patient has made near total recovery.

\section{Discussion}

The known complications of retained intracardiac missile are bleeding, perforation (cardiac tamponade), thrombus formation, embolization, rhythm disturbances, and infection. These complications are usually related to the size and location of the missile. The natural course, long-term complications, and migratory potential are unpredictable and are not well documented. A non-operative approach is appropriate for a stable, asymptomatic patient. Many right and left ventricular wall injuries have been treated non-operatively $(9,10)$. Localization of the bullet is another challenge and at times requires specialized imaging techniques (11). While in literature it is recommended that intra-cardiac gunshot injuries be managed conservatively (non-surgically) (8), surgical intervention was necessary in this case as cardiac function was evidently deteriorating.

The totality of the patient care attests to the costly venture the treatment of missile wounds tend to be. In his case, he needed cardiothoracic, orthopedic, maxillofacial, and critical care specialists to guide his care over the 41 days stay. It is difficult to imagine the scenario in the rest of the country where the constellation of specialists and critical care support as seen here, is the exception. In conclusion, while elective removal of an intra-myocardial bullet remains a controversial subject, the successful removal of the bullet and the incident free post operative recovery in this case adds to the justification of surgery, where there are signs of compromised cardiac function.This case presentation illustrates the burden of firearm injury on a health facility and resources, including the need for highly skilled multidisciplinary personnel to perform the delicate surgical procedures.

\section{Acknowledgements}

Prof. Gakuu, Dr. Kariuki, Dr. Gathua, Dr. Moniz, Z.Ngumi The Nairobi Hospital and the theatre staff

The Doctor who consented to have his near fatal traumatic experience presented in this paper

\section{References}

1. Krug E.(ed).Injury: A leading cause of Global Burden of Disease ; Geneva World health organization, 1999, pp. 1-4.

2. WHO injuries and violence prevention department in Small Arms Global Health a contribution to UN conference on illicit trade in Small Arms and light Weapons, July 2001,pp.920.

3. Browin MM. Editorial, Small Arms Survey. Graduate Institute of International studies, Geneva. Oxford University Press V1, 2003

4. Ryan J. Warfare injuries in Bailey and Love short practice of surgery 23rd edition edited by Russel N.S.W and C.J.K Bulstrade Arnode published 2000,281-190.

5. Thompson EC, Block EF, Mancini ,MC: Management of BB shot wounds to the heart. J Trauma 1996;40(1):168-170.

6. Galante J, London JA: Left ventricular bullet embolus: A case report and review of the literature ; Jemermed.2007.09.057

7. Poston RS, Sloane RW Jr, Morgan BR, et al. Elective removal of an intra-myocardial bullet. South Med J 2001;94:464-466

8. J Mahenthiran, H. Weerracody: Bullet in the heart ; Clin Cardiol 1999, (22) 128.

9. Degiannis E. Velmahos G. Krawczykowski D. Levy RD Souter I. Saadia R.: Penetrating injuries of the subclavian vessels. 1994 Br J Surg. 81(4):524-6.

10. Tsakiris P,Cleantone J P E and lowinie M A : Airway status in civilian maxillofacial gunshot Injuries in Johannesburg South Africa; S Afr Med. J 2002,92:803-806

11. Hashimi,MW, Jenkins DR, McGwier BW, Massey CV, Alpert MA; Comparative Efficacy of Transthoracic and Transesophageal Echocardiography in Detection of an Intracardiac Bullet Fragment: Chest J, 1994;106;299-300 